\title{
Erratum: Hydrogen Permeability, Diffusivity, and Solubility of SUS 316L Stainless Steel in the Temperature Range 400 to $800{ }^{\circ} \mathrm{C}$ for Fusion Reactor Applications
}

\author{
[J. Korean Phys. Soc. 59, 3019 (2011)]
}

S. K. LEE, H. S. KIM and S. J. NoH*

Department of Applied Physics, Institute of Nanosensor and Biotechnology, Dankook University, Yongin 448-701, Korea

\section{J. H. HAN}

Center for Advance Research in Fusion Reactor Engineering, Seoul National University, Seoul 151-742, Korea

DOI: $10.3938 / \mathrm{jkps} .61 .168$

Figure 3 was submitted incorrectly. The corrections affected by our error are described as follows;

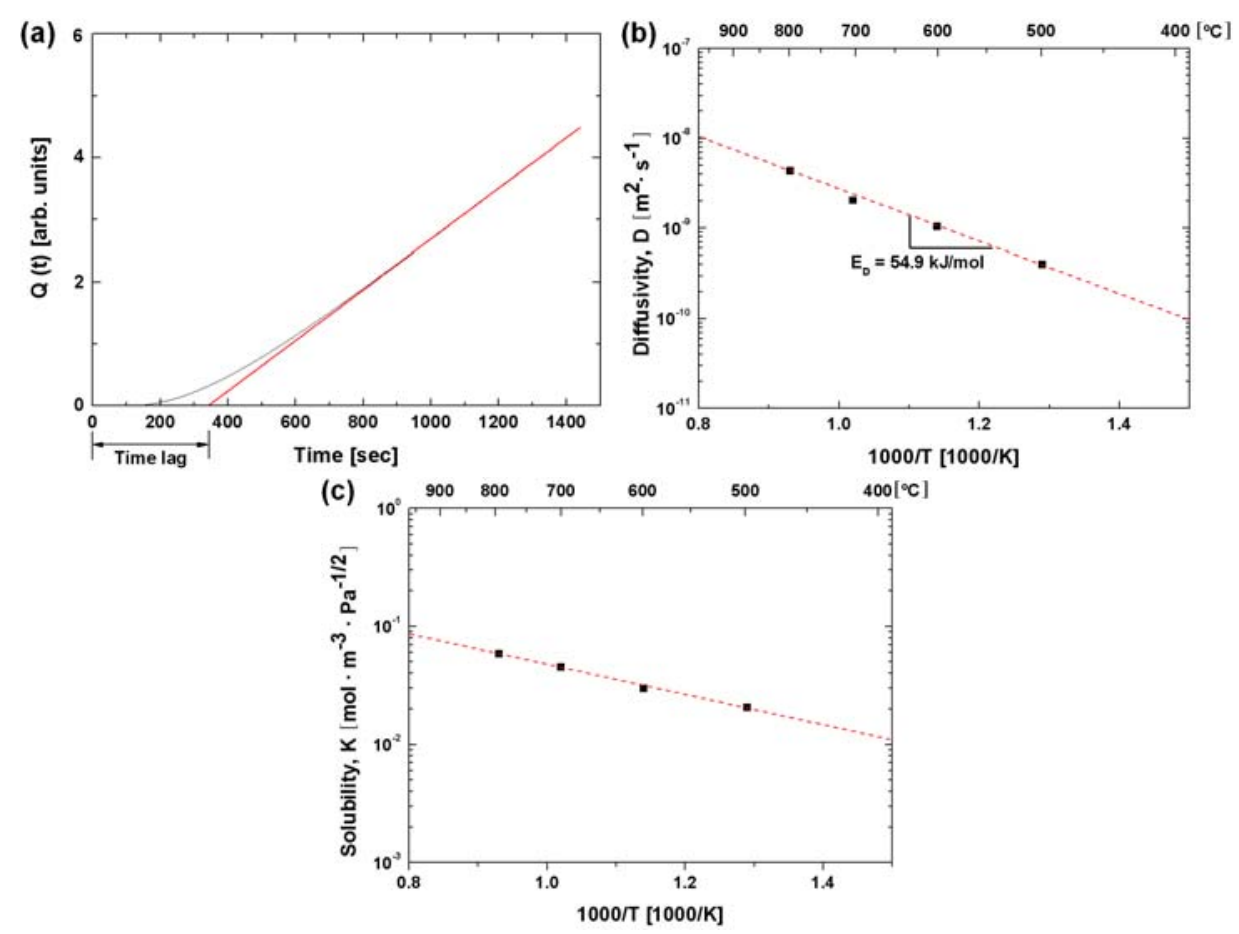

The time-lag $t_{o}$ (in the results and discussion) is affected by our error; the value (reported as 184 sec) should be corrected to $345 \mathrm{sec}$. The activation energy of the diffusivity (in the results and discussion and in the conclusion) is also affected by our error; the value (reported as $66.1 \mathrm{~kJ} / \mathrm{mol}$ ) should be corrected to $54.9 \mathrm{~kJ} / \mathrm{mol}$. 